\title{
Volatile anesthetics in cardiac surgery: the impalpable benefit
}

\author{
Annalaura Di Pumpo, Chiara Candela, Fabrizio Cucciniello, Domenico Sarubbi, Felice Eugenio Agrò
}

Department of Anesthesia and Intensive Care Unit, Università Campus Bio-Medico di Roma, Rome 00128, Italy.

Correspondence to: Dr. Annalaura Di Pumpo, Department of Anesthesia and Intensive Care Unit, Università Campus BioMedico di Roma, Via Alvaro del Portillo 200, Rome 00128, Italy. E-mail: a.dipumpo@unicampus.it

How to cite this article: Di Pumpo A, Candela C, Cucciniello F, Sarubbi D, Agrò FE. Volatile anesthetics in cardiac surgery: the impalpable benefit. Vesse/ P/us 2018;2:41. http://dx.doi.org/10.20517/2574-1209.2018.38

Received: 29 May 2018 First Decision: 17 Oct 2018 Revised: 5 Nov 2018 Accepted: 5 Nov 2018 Published: 12 Dec 2018

Science Editors: Mario F. L. Gaudino, Cristiano Spadaccio Copy Editor: Cui Yu Production Editor: Huan-Liang Wu

\begin{abstract}
Nowadays, there are numerous studies demonstrating that volatile anesthetics reduce mortality and morbidity with a cardio-protective effect. The mechanisms involved in protecting perioperative cardiac ischemic damage provided by desflurane and sevoflurane are not fully known. Volatile anesthetics are commonly used in cardiac surgery. This minireview aims to summarize the mechanism of action for cardio-protection of volatile anesthetics and discuss the potential therapeutic implications. Human studies have shown that volatile anesthetics can reduce mortality, but also the use of mechanical ventilation in cardiac patients, especially coronary artery bypass grafting. In contrast, total intravenous anesthesia has not shown any significant benefit compared to halogenated agents. Volatile anesthetics are among the few drugs that affect survival in the perioperative period. In addition, they can be administered in areas other than cardiac surgery due to their cardioprotective effects, which may add future perspectives in their use.
\end{abstract}

Keywords: Volatile anesthetics, preconditioning, cardiac surgery, cardio-protection

\section{INTRODUCTION}

Nowadays, there are numerous studies demonstrating that volatile anesthetics reduce mortality and morbidity with a cardio-protective effect ${ }^{[1]}$. The mechanisms involved in protecting perioperative cardiac ischemic damage provided by desflurane and sevoflurane are not fully known.

In 1986, for the first time, this phenomenon is described as a response to short periods of sublethal ischemia leading to a protection against a subsequent lethal ischemia ${ }^{[2]}$. 
In 1988, Warltier et al. ${ }^{[3]}$ demonstrated that the use of halothane or isoflurane improved left ventricular systolic function. Subsequently, Cason et al ${ }^{[4]}$ introduced the concept of cardiac pre-conditioning of the halogenates, demonstrating that their administration before ischemia protects the myocardium from a subsequent lesion.

Since then, numerous studies both in vivo and in animals have demonstrated this phenomenon ${ }^{[5-9]}$.

An international consensus conference included volatile agents among the few drugs that would decrease perioperative mortality in cardiac surgery ${ }^{[10]}$.

This mini-review aims to summarize the mechanism of action for cardioprotection of volatile anesthetics and discuss the potential therapeutic implications.

\section{MECHANISM OF ACTION FOR CARDIAC PROTECTION}

Thanks to the use of animal models, we have been able to relate the ischemia/reperfusion injury with the cardio-protection of volatile agents and establish a cause-effect relationship between the volatile anesthetic and cardio-diagnostic points such as the reduction of death cellular, improvement of contractile function and decrease in the incidence of arrhythmias ${ }^{[11]}$.

A dose-dependent signal appears to be based on anesthetic cardiac preconditioning: the degree of protection depends on the concentration of the drug administered and the duration of the administration ${ }^{[12-15]}$. Lange et al ${ }^{[16]}$ has shown that there is a threshold for the preconditioning of desflurane which is included between 0.5 and 1.0 minimum alveolar concentration. This threshold may decrease through the administration of desfuorane by intervals. As soon as the level of cardioprotection from desflurano is reached, it cannot be further improved with desflurane increments.

All the volatile anesthetics that we use daily (desflurane, halothane, isoflurane and sevoflurane) produce cardiac preconditioning because they have the same mechanism of action but different power ${ }^{[16]}$.

Two types of preconditioning have been identified: one early, which lasts about 1 or $2 \mathrm{~h}$, and one late, which occurs after $24 \mathrm{~h}$ and lasts up to $72 \mathrm{~h}$. Early and late preconditioning have many characteristics, but probably involve different paths [Table 1 $]^{[5]}$.

Myocardial reperfusion has two effects: decreases cardiac damage but activates apoptosis of the cells producing myocardial dysfunction, which is linked to mitochondrial dysfunction, in particular, at the opening of mitochondrial permeability transition pores (mPTPs).

During reperfusion, volatile anesthetics avoid the opening of transitional pores of the mitochondrial permeability. In this way the different mechanisms of apoptosis are inhibited ${ }^{[17,18]}$. In addition, anesthetics act on the signaling pathways linked to adrenergic receptors and adenosine bradykinin, both involved in cardioprotection $^{[19]}$.

Myocardial post-conditioning by the halogenates is due to various cellular mechanisms ${ }^{[16-18]}$ : modulation of L-type calcium channels, inhibition of the release of reactive oxygen species from the mitochondria to the cytoplasm, mPTP closed, stimulation of G proteins coupled with $\beta$-adrenergic receptors.

Various pathways, including the activation of Gi (GiPCR) coupled Gi (inhibitors), phospholipase B and D receptors, diacylglycerol and protein kinase $C$, are involved, activating KATP channels ${ }^{[5]}$. KATP channels are inhibited by intracellular ATP physiological concentrations and, when opened, produce a repolarizing internal potassium stream. MitKATP channel antagonists may inhibit the cardioprotective function of des- 


\begin{tabular}{ll}
\hline Early preconditioning & \multicolumn{1}{c}{ Late preconditioning } \\
\hline It begins early & It begins $12-24 \mathrm{~h}$ after ischemia \\
Duration of $1-2 \mathrm{~h}$ & Duration of $72 \mathrm{~h}$ \\
It is due to the accumulation of adenosine & It is due to gene up-regulation \\
\hline
\end{tabular}

flurane and sevoflurane. The opening of the canal would lead to the reduction of the swelling of the intermembrane space after ischemia, preserving the structure and mitochondrial function. Depolarization of the mitochondrial inner membrane also prevents the opening of the mPTP and inhibits the exchange of $\mathrm{Na}^{+}-\mathrm{H}^{+}$, attenuating $\mathrm{Ca}^{2+}$ overload and cellular edema ${ }^{[5]}$. Interferences have been described with the apoptotic cascade mediated by $\mathrm{Bcl}-2$-associated death promoter and Bcl-2-associated $\mathrm{X}$ proteins and caspases 9 , in addition to activation of nitric oxide endothelial synthas $e^{[5,20,21]}$ which may give a cardioprotective effect. Also reactive oxygen species (ROS) have an important task: the opening of the KATP channels causes an increase in the intracellular concentrations of ROS, at the same time, the production of ROS can also precede and cause the opening of the KATP channels. Activators of the KATP channel and sevoflurane may attenuate the overproduction of ROS during reperfusion. Therefore, halogenates, in order to achieve preconditioning, must cause ROS production. Preconditioning, in turn, allows a reduction of ROS excess, during reperfusion ${ }^{[21,22]}$. Volatile anesthetics also reduce platelet adhesion to the vascular wall after ischemia ${ }^{[23]}$.

Regarding the late preconditioning, it is due to cardioprotective proteins that are expressed after the translation of the first genes induced by cardiac preconditioning. The most common genes expressed virtually by any type of stress conditioning include antioxidants such as superoxide dismutase, glutathione peroxidase and heme oxygenase, genes associated with cell defense [heat shock proteins(HSP) such as HSP70 and HSP10, aldose reductase, Bcl-xS] and cycloid-oxygenase $2^{[24]}$.

Ischemic preconditioning is the process implemented by the myocardial tissue at the cellular level that provides myocardial protection against the damage due to the ischemia/reperfusion phenomenon in the cardiac tissue $^{[25]}$.

After administration of volatile agents, the systolic function improves because we have a reduction in myocardial oxygen consumption due to depression of myocardial contractility and improvement of blood flow in several capillary beds ${ }^{[26]}$.

Human studies have shown that volatile anesthetics can reduce mortality, but also the use of mechanical ventilation in cardiac patients, especially coronary artery bypass grafting (CABG). In contrast, total intravenous anesthesia (TIVA) (and more specifically propofol) has not shown any significant benefit compared to halogenated agents. The studies of Fortis et al. ${ }^{[27]}$ and Schilling et al ${ }^{[28]}$ have shown that halogenates lead to a reduction of the inflammatory response in acute lung injury. In addition, the volatile agents cause neuroprotection after brain damage ${ }^{[29]}$, reduce hepatic damage ${ }^{[30]}$ and the incidence of acute renal injury after an ischemic insult ${ }^{[31]}$. As a result, volatile anesthetics can also play an important role in preventing cardiac surgery complications.

\section{CLINICAL IMPLICATIONS}

In 2011, there was an international consensus conference that included volatile agents among the few drugs that would decrease perioperative mortality in cardiac surgery ${ }^{[10]}$. Volatile anesthetics (desflurane, isoflurane and sevoflurane) have pharmacological characteristics that generate cardiac protection, unlike the drugs used for TIVA.

Indeed, the 2007 Landoni meta-analysis showed a reduction in perioperative cardiac troponin release and reduced mortality in patients receiving volatile anesthetics compared to patients receiving a TIVA ${ }^{[32]}$. 
To endorse the hypothesis, that from these benefits we can obtain a reduced mortality rate in patients who receive volatile agents, there are numerous studies. These results led to an ordinary use of volatile anesthetics compared to TIVA, although propofol is a drug that has a much lower cost than halogenated drugs. For example, a bottle of sevoflurane costs 74 euro, while a bottle of $2 \%$ propofol costs 1.6 euro.

There are no studies that discourage the use of propofol $^{[33]}$ but we must remember that when using TIVA in cardiac surgery we do not have remote ischemic preconditioning ${ }^{[34]}$, due to the inhibition of the organoprotective properties of this technique ${ }^{[35]}$. Furthermore, there are at least 8 studies showing an increase in mortality with the use of TIVA, while there is no study that demonstrates an increase in survival with $\operatorname{TIVA}^{[32,36,37]}$.

\section{DISCUSSION}

In the meta-analysis of Zangrillo et al. ${ }^{[38]}$, it has been shown that halogenated agents can decrease mortality and have additional cardioprotective effects compared to TIVA. In this meta-analysis, it has been shown that in patients undergoing cardiac surgery, the use of volatile agents and/or the combination of volatile agents with remote preconditioning produces lower mortality compared to TIVA with longer follow-up. The metaanalysis of the Bayesian network compares different groups of patients both directly and indirectly, with a consolidated method in clinical research. This meta-analysis includes all randomized trials in adult cardiac systems that compare volatile agents, TIVA and remote ischemic preconditioning. This study is an invitation to use volatile anesthetics during general anesthesia because there is no evidence of beneficial properties of TIVA except when combined with volatile agents. This meta-analysis has some limitations: most of the studies included in the study are small, single centers and not double-blind. In fact, for example, some authors do not preside over whether patients taking drugs such as sulfonylurea, theophylline or allopurinol have been excluded, as these drugs appear to influence the preconditioning mechanism. Another limitation may be the use of intraoperative opioids. In fact, opioids reduce the cardiovascular effect and can hinder the cardioprotective effects of volatile agents ${ }^{[38]}$.

Furthermore, ischemic preconditioning can lower postoperative cardiac biomarker levels ${ }^{[39,40]}$ and even mortality during cardiac surgery ${ }^{[4]]}$.

The first study ${ }^{[32]}$, published in 2007 , which showed a greater survival of patients subjected to halogenated agents compared to TIVA, was a meta-analysis of small randomized clinical trials. The meta-analysis showed that sevoflurane and desflurane were associated with significant reductions in myocardial infarction $(2.4 \%$ vs. $5.1 \%$ ) and mortality ( $0.4 \%$ vs. $1.6 \%$ ). In a large multi-center study, patients who received sevoflurane showed a 30-day lower postoperative mortality than those who received TIVA $(2.2 \% \text { vs. } 3.1 \%)^{[36]}$. Instead, De Hert et al. ${ }^{[42]}$ did not find any difference in the post-operative troponin T release between volatile anesthetics and TIVA but showed a significant difference in one-year mortality among the various groups (3.3\% in the sevoflurane group, $6.7 \%$ in the desflurane group and $12.3 \%$ in the TIVA group $(P=0.034)^{[42]}$. A large multi-center study analyzed the 30-day mortality rate in patients undergoing CABG where halogenated anesthetics or TIVA was used. Mortality was lower with halogenates and the mortality rate was lower than with the use of halogenated anesthetics ${ }^{[43]}$. A recent meta-analysis by Landoni showed a $50 \%$ reduction in mortality compared to TIVA (desflurane $1.8 \%$ vs. $4.0 \%$, isoflurane $0.7 \%$ vs. $2.0 \%$ and sevoflurane $1.2 \%$ vs. $3.0 \%{ }^{[44]}$.

In contrast, some authors have shown that patients with severe preoperative ischemic stress benefit from TIVA because of its antioxidant effects ${ }^{[45]}$. However, no increase in survival with TIVA has been demonstrated, indeed some studies have shown worse outcomes if propofol is compared with halogenates ${ }^{[36]}$.

There is disagreement about the type of cardiac surgery that benefits most from halogenated cardiac protection. Most studies have shown that cardioprotection occurs mainly in CABG while the evidence of haloge- 
nates in valve surgery is controversial ${ }^{[46,47]}$. A 2006 study showed that the use of sevoflurane leads to better preservation of myocardial function and less postoperative release of troponin I in patients undergoing aortic valve replacement ${ }^{[47]}$. In contrast, the study of Pinaud et al ${ }^{[48]}$ in 2015, demonstrated that preconditioning does not have cardioprotective effects in patients undergoing valve surgery without CABG.

There are no clear advantages of the use of volatiles in valve surgery. A first reason is that myocardial infarction can simulate a preconditioned state by improving the effect of halogenated agents ${ }^{[49]}$. In fact, as demonstrated by Murry et al ${ }^{[2]}$, short periods of transient myocardial ischemia protect the heart from extensive damage in longer periods of ischemia. Furthermore, valvular surgery causes an increase in troponin due to higher surgical injuries and anatomical changes that modify the geometry and function of the left ventricle, with acute increase in the afterload, especially in mitral valve surgery ${ }^{[50]}$.

We must remember that when using TIVA in cardiac surgery we do not have remote ischemic preconditioning $^{[34]}$. This led to the demonstration that TIVA leads to an increase in mortality, while there is no study showing that it increases survival ${ }^{[32,36,37]}$.

However, TIVA remains widely used for rapid interventions. As demonstrated by Çaparlar et al ${ }^{[51]}$, patients eligible for the preferential ward were older and the time for rapid suitability was shorter in the TIVA group compared to sevoflurane ( $82.1 \%$ vs. $57.5 \%$ and $8 \mathrm{~min} v s .12 \mathrm{~min}, P<0.05)$.

At the same time, it must be stated that volatile agents, such as desfuorane, are proving to be an excellent alternative to propofol for fast-track interventions ${ }^{[52,53]}$.

Thus we obtain two results: the cardiac preconditioning given by the volatile agent and rapid extubation times.

\section{CONCLUSION}

Volatile anesthetics are among the few drugs that affect survival in the perioperative period ${ }^{[54]}$. In addition, they can be administered in other areas other than cardiac surgery due to their cardioprotective effects, which may add future perspectives in their use.

Notwithstanding the numerous studies in favor of volatile anesthetics, it is necessary to give a definitive answer regarding the greater survival of patients with the simple use of volatile anesthetics, with randomized trials provided with a very large sample. The largest study currently underway is recruiting 10,600 participants and has the task of conclusively demonstrating how the simple use of a halogenated agent improves one-year survival in patients undergoing CABG.

\section{DECLARATIONS}

\section{Authors' contributions}

Data collection, manuscript revision: Di Pumpo A

Study design, literature analysis, manuscript drafting: Di Pumpo A, Candela C

Literature analysis, manuscript critical revision: Cucciniello F, Sarubbi D

Study design, manuscript critical revision: Agrò FE

\section{Availability of data and materials}

Literature search (Pubmed, Scopus). 


\section{Financial support and sponsorship}

None.

\section{Conflicts of interest}

All authors declared that there are no conflicts of interest.

\section{Ethical approval and consent to participate}

Not applicable.

\section{Consent for publication}

Approved by the institution where the work was carried out.

\section{Copyright}

(C) The Author(s) 2018.

\section{REFERENCES}

1. Landoni G, Fochi O, Torri G. Cardiac protection by volatile anaesthetics: a review. Curr Vasc Pharmacol 2008;6:108-11.

2. Murry CE, Jennings RB, Reimer KA. Preconditioning with ischemia: a delay of lethal cell injury in ischemic myocardium. Circulation 1986;74:1124-36.

3. Warltier DC, al-Wathiqui MH, Kampine JP, Schmeling WT. Recovery of contractile function of stunned myocardium in chronically instrumented dogs is enhanced by halothane or isoflurane. Anesthesiology 1988;69:552-65.

4. Cason BA, Gamperl AK, Slocum RE, Hickey RF. Anesthetic-induced preconditioning: previous administration of isoflurane decreases myocardial infarct size in rabbits. Anesthesiology 1997;87:1182-90.

5. Chiari P, Bouvet F, Piriou V. Anaesthetic-induced myocardial preconditioning: fundamental basis and clinical implications. Ann Fr Anesth Reanim 2005;24:383-96. (in French)

6. Varadarajan SG, An J, Novalija E, Stowe DF. Sevoflurane before or after ischemia improves contractile and metabolic function while reducing myoplasmic $\mathrm{Ca}(2+)$ loading in intact hearts. Anesthesiology 2002;96:125-33.

7. Ross S, Foëx P. Protective effects of anaesthetics in reversible and irreversible ischaemia-reperfusion injury. Br J Anaesth $1999 ; 82: 622-32$.

8. Toller WG, Kersten JR, Pagel PS, Hettrick DA, Warltier DC. Sevoflurane reduces myocardial infarct size and decreases the time threshold for ischemic preconditioning in dogs. Anesthesiology 1999;91:1437-46.

9. Preckel B, Schlack W, Comfère T, Obal D, Barthel H, et al. Effects of enflurane, isoflurane, sevoflurane and desflurane on reperfusion injury after regional myocardial ischaemia in the rabbit heart in vivo. Br J Anaesth 1998;81:905-12.

10. Landoni G, Augoustides JG, Guarracino F, Santini F, Ponschab M, et al. Mortality reduction in cardiac anesthesia and intensive care: results of the first International Consensus Conference. Acta Anaesthesiol Scand 2011;55:259-66.

11. Muntean DM, Ordodi V, Ferrera R, Angoulvant D. Volatile anaesthetics and cardioprotection: lessons from animal studies. Fundam Clin Pharmacol 2013;27:21-34.

12. Riess ML, Kevin LG, Camara AK, Heisner JS, Stowe DF. Dual exposure to sevoflurane improves anesthetic preconditioning in intact hearts. Anesthesiology 2004;100:569-74.

13. Ludwig LM, Patel HH, Gross GJ, Kersten JR, Pagel PS, et al. Morphine enhances pharmacological preconditioning by isoflurane: role of mitochondrial K(ATP) channels and opioid receptors. Anesthesiology 2003;98:705-11.

14. Kato R, Foëx P. Myocardial protection by anesthetic agents against ischemia-reperfusion injury: an update for anesthesiologists. Can J Anesth 2002;49:777-91.

15. Kehl F, Krolikowski JG, Mraovic B, Pagel PS, Warltier DC, et al. Is isoflurane-induced preconditioning dose related? Anesthesiology 2002;96:675-80.

16. Lange M, Redel A, Lotz C, Smul TM, Blomeyer C, et al. Desflurane-induced postconditioning is mediated by beta-adrenergic signalling: role of beta 1 - and beta 2 -adrenergic receptors, protein kinase A, and calcium/calmodulin-dependent protein kinase II. Anesthesiology 2009; 110:516-28.

17. Halestrap AP, Clarke SJ, Javadov S. Mitochondrial permeability transition pore opening during myocardial reperfusion--a target for cardioprotection. Cardiovasc Res 2004;61:372-85.

18. Di Lisa F, Menabò R, Canton M, Barile M, Bernardi P. Opening of the mitochondrial permeability transition pore causes depletion of mitochondrial and cytosolic NAD + and is a causative event in the death of myocytes in postischemic reperfusion of the heart. $\mathrm{J}$ Biol Chem 2001;276:2571-5.

19. Landoni G, Lopez-Delgado JC, Sartini C, Tamà S, Zangrillo A. Halogenated agents and cardiovascular surgery: has mortality really decreased? Curr Vasc Pharmacol 2018;16:336-43. 
20. Garcia-Dorado D, Rodriguez-Sinovas A, Ruiz-Meana M, Inserte J, Agulló L, et al. The end-effectors of preconditioning protection against myocardial cell death secondary to ischemia reperfusion. Cardiovasc Res 2006;70:274-85.

21. Novalija E, Varadarajan SG, Camara AK, An J, Chen Q, et al. Anesthetic preconditioning: triggering role of reactive oxygen and nitrogen species in isolated hearts. Am J Physiol Heart Circ Physiol 2002;283:H44-52.

22. Zweier JL, Talukder MA. The role of oxidants and free radicals in reperfusion injury. Cardiovasc Res 2006;70:181-90.

23. Heindl B, Becker BF, Zahler S, Conzen PF. Volatile anaesthetics reduce adhesion of blood platelets under low-flow conditions in the coronary system of isolated guinea pig hearts. Acta Anaesthesiol Scand 1998;42:995-1003.

24. Das DK, Maulik N. Cardiac genomic response following preconditioning stimulus. Cardiovasc Res 2006;70:254-63.

25. Heusch G, Schulz R. Remote preconditioning. J Mol Cell Cardiol 2002;34:1279-81.

26. Hartman JC, Pagel PS, Proctor LT, Kampine JP, Schmeling WT, et al. Influence of desflurane, isoflurane and halothane on regional tissue perfusion in dogs. Can J Anaesth 1992;39:877-87.

27. Fortis S, Spieth PM, Lu WY, Parotto M, Haitsma JJ, et al. Effects of anesthetic regimes on inflammatory responses in a rat model of acute lung injury. Intensive Care Med 2012;38:1548-55.

28. Schilling T, Kozian A, Senturk M, Huth C, Reinhold A, et al. Effects of volatile and intravenous anesthesia on the alveolar and systemic inflammatory response in thoracic surgical patients. Anesthesiology 2011;115:65-74.

29. Yang Q, Dong H, Deng J, Wang Q, Ye R, et al. Sevoflurane preconditioning induces neuroprotection through reactive oxygen speciesmediated up-regulation of antioxidant enzymes in rats. Anesth Analg 2011;112:931-7.

30. Beck-Schimmer B, Breitenstein S, Bonvini JM, Lesurtel M, Ganter M, et al. Protection of pharmacological postconditioning in liver surgery: results of a prospective randomized controlled trial. Ann Surg 2012;256:837-44.

31. Lee HT, Kim M, Kim J, Kim N, Emala CW. TGF-beta1 release by volatile anesthetics mediates protection against renal proximal tubule cell necrosis. Am J Nephrol 2007;27:416-24.

32. Landoni G, Biondi-Zoccai GG, Zangrillo A, Bignami E, D'Avolio S, et al. Desflurane and sevoflurane in cardiac surgery: a meta-analysis of randomized clinical trials. J Cardiothorac Vasc Anesth 2007;21:502-11.

33. Pasin L, Landoni G, Cabrini L, Borghi G, Taddeo D, et al. Propofol and survival: a meta-analysis of randomized clinical trials. Acta Anaesthesiol Scand 2015;59:17-24.

34. Meybohm P, Bein B, Brosteanu O, Cremer J, Gruenewald M, et al. A multicenter trial of remote ischemic preconditioning for heart surgery. N Engl J Med 2015;373:1397-407.

35. Landoni G, Baiardo Redaelli M, Votta CD. Remote ischemic preconditioning and cardiac surgery. N Engl J Med 2016;374:489.

36. Jakobsen CJ, Berg H, Hindsholm KB, Faddy N, Sloth E. The influence of propofol versus sevoflurane anesthesia on outcome in 10,535 cardiac surgical procedures. J Cardiothorac Vasc Anesth 2007;21:664-71.

37. Uhlig C, Bluth T, Schwarz K, Deckert S, Heinrich L, et al. Effects of volatile anesthetics on mortality and postoperative pulmonary and other complications in patients undergoing surgery: a systematic review and meta-analysis. Anesthesiology 2016;124:1230-45.

38. Zangrillo A, Musu M, Greco T, Di Prima AL, Matteazzi A, et al. Additive effect on survival of anaesthetic cardiac protection and remote ischemic preconditioning in cardiac surgery: a bayesian network meta-analysis of randomized trials. PLoS One 2015;10:e0134264.

39. Zhou C, Liu Y, Yao Y, Zhou S, Fang N, et al. $\beta$-blockers and volatile anesthetics may attenuate cardioprotection by remote preconditioning in adult cardiac surgery: a meta-analysis of 15 randomized trials. J Cardiothorac Vasc Anesth 2013;27:305-11.

40. Yang L, Wang G, Du Y, Ji B, Zheng Z. Remote ischemic preconditioning reduces cardiac troponin I release in cardiac surgery: a metaanalysis. J Cardiothorac Vasc Anesth 2014;28:682-9.

41. Thielmann M, Kottenberg E, Kleinbongard P, Wendt D, Gedik N, et al. Cardioprotective and prognostic effects of remote ischaemic preconditioning in patients undergoing coronary artery bypass surgery: a single-centre randomised, double-blind, controlled trial. Lancet 2013;382:597-604.

42. De Hert S, Vlasselaers D, Barbé R, Ory JP, Dekegel D, et al. A comparison of volatile and non volatile agents for cardioprotection during on-pump coronary surgery. Anaesthesia 2009;64:953-60.

43. Bignami E, Biondi-Zoccai G, Landoni G, Fochi O, Testa V, et al. Volatile anesthetics reduce mortality in cardiac surgery. J Cardiothorac Vasc Anesth 2009;23:594-9.

44. Landoni G, Greco T, Biondi-Zoccai G, Nigro Neto C, Febres D, et al. Anaesthetic drugs and survival: a Bayesian network meta-analysis of randomized trials in cardiac surgery. Br J Anaesth 2013;111:886-96.

45. Marik PE. Propofol: an immunomodulating agent. Pharmacotherapy 2005;25:28S-33S.

46. Meybohm P, Bein B, Brosteanu O, Cremer J, Gruenewald M, et al. A multicenter trial of remote ischemic preconditioning for heart surgery. N Engl J Med 2015;373:1397-407.

47. Cromheecke S, Pepermans V, Hendrickx E, Lorsomradee S, Ten Broecke PW, et al. Cardioprotective properties of sevoflurane in patients undergoing aortic valve replacement with cardiopulmonary bypass. Anesth Analg 2006;103:289-96.

48. Pinaud F, Corbeau JJ, Baufreton C, Binuani JP, De Brux JL, et al. Remote ischemic preconditioning in aortic valve surgery: results of a randomized controlled study. J Cardiol 2016;67:36-41.

49. De Hert SG, Turani F, Mathur S, Stowe DF. Cardioprotection with volatile anesthetics: mechanisms and clinical implications. Anesth Analg 2005;100:1584-93.

50. Goldfine H, Aurigemma GP, Zile MR, Gaasch WH. Left ventricular length-force-shortening relations before and after surgical correction of chronic mitral regurgitation. J Am Coll Cardiol 1998;31:180-5.

51. Çaparlar CÖ, Özhan MÖ, Süzer MA, Yazicioğlu D, Eşkin MB, et al. Fast-track anesthesia in patients undergoing outpatient laparoscop- 
ic cholecystectomy: comparison of sevoflurane with total intravenous anesthesia. J Clin Anesth 2017;37:25-30.

52. Jain A, Gombar S, Ahuja V. Recovery profile after general anaesthesia in paediatric ambulatory surgeries: desflurane versus propofol. Turk J Anaesthesiol Reanim 2018;46:21-7.

53. Liu TC, Lai HC, Lu CH, Huang YS, Hung NK, et al. Analysis of anesthesia-controlled operating room time after propofol-based total intravenous anesthesia compared with desflurane anesthesia in functional endoscopic sinus surgery. Medicine (Baltimore) 2018;97:e9805.

54. Landoni G, Pisano A, Lomivorotov V, Alvaro G, Hajjar L, et al. Randomized evidence for reduction of perioperative mortality: an updated consensus process. J Cardiothorac Vasc Anesth 2017;31:719-30. 